\title{
Improvement in design method of rock-socketed pile based on enhancement of shaft resistance
}

\author{
Haofeng Xing and Jin $\mathrm{Wu}^{*}$ \\ Department of Geotechnical Engineering, Tongji University, Shanghai 200092, China \\ *Correspondence Author: 360080978@163.com
}

\begin{abstract}
Large-diameter rock-socketed piles are typically used to support a bridge with a long span or high piers. To study their mechanical properties in mountainous areas, field loading tests based on a distributed fiber sensing technique were conducted. The test results indicate that the shaft resistance comes into play earlier than the tip resistance and that an upper load occurs mainly through the shaft resistance. When the load-sharing ratio of the tip resistance exceeds $10 \%$, an enhancement in the shaft resistance occurs, which becomes more obvious with an increase in the ratio. The shaft resistance and the tip resistance are not independent, but interact with each other. An increase in tip resistance can promote the effective role of the shaft resistance. According to the field test results, the design method for rock-socketed piles was improved based on the shaft resistance enhancement. The calculation results indicate that the rock-socketed length of a pile can be effectively shortened using this method, thereby obtaining considerable economic benefits.
\end{abstract}

Keywords: Rock-socketed pile; distributed fiber sensing technique; enhancement phenomenon; design method.

\section{INTRODUCTION}

A pile foundation is one of the most common types of structural foundation, and large diameter rock-socketed piles are usually applied to support bridges in mountainous areas. At present, a rock-socketed pile can be considered as a friction pile, end load pile, or end load friction pile according to the load characteristics. Different design methods have been put forward for rock-socketed piles, such as the elastic design method proposed by Pells and Turner (1979), nonlinear design method put forward by Williams and Johnston (1980), and elastic-plastic design method presented by Rowe and Armitage (1987). Actually, the load function of the tip resistance is usually ignored in engineering applications owing to limitations in construction technologies (Seidel \& Collingwood, 2001). In addition, many different empirical calculation formulas for the load capacity of rock-socketed piles based on the shaft resistance have been proposed (Carrubba, 1997; Zhang \& Einstein, 1999; Charles et al., 2001; Horvath et al., 2011; Rosenberg et al., 2011). With the continuous development of construction technologies applied to rock-socketed piles, further researches have indicated that the effect of the tip resistance should not be ignored, and many empirical formulas adding to this effect have been put forward. With such methods, the shaft resistance and the tip resistance are considered to be mutually independent and do not affect each other; in addition, the load capacity of rock-socketed piles is determined through the linear superposition of these two types of resistance (Rowe \& Armitage, 1987; Zhang \& Einstein, 1999; Vipulanandan et al., 2007; Zhang, 2010). In fact, designers often increase the rock-socketed length or pile diameter intentionally to ensure design safety in practical engineering applications, which may increase the cost of construction. In recent years, more than 200,000 rock-socketed piles will be used in infrastructure construction, such as high-speed railways, expressways, and long span bridges, in Guizhou Province in China, and if the length of each rock-socketed pile can be shortened by $1 \mathrm{~m}$, over 3 million dollars in construction costs can be saved. Simultaneously, the safety of the construction will be improved, and the construction period will be shortened. Therefore, it is necessary to improve the design method of rock-socketed piles based on the interaction between the shaft resistance and the tip resistance. 
In this study, field tests based on the Hezhang Bridge project in Guizhou Province, China were carried out using a distributed fiber sensing technique to improve the design method for large-diameter rock-socketed piles.

\section{PROJECT OVERVIEW}

Hezhang Bridge is one of the main components of the Biji-Weining Expressway project. Figure 1 shows a sketch of the bridge. Pier no. 11 is the main support pillar, with a height of $195 \mathrm{~m}$ and a designed axial force of 1,000 MN, and the pier is supported by 20 rock-socketed piles $2.5 \mathrm{~m}$ in diameter and $40 \mathrm{~m}$ in length. Figure 2 shows the layout of the rock-socketed piles at the pier no. 11 site. The pier and piles are connected through a pier cap of $27 \times 23 \times 36 \mathrm{~m}^{3}$ in size. The total load of the pile group foundation is about $700 \mathrm{MN}$ when considering the dead weight of the pile cap, and thus the maximum load of single pile is $35 \mathrm{MN}$.

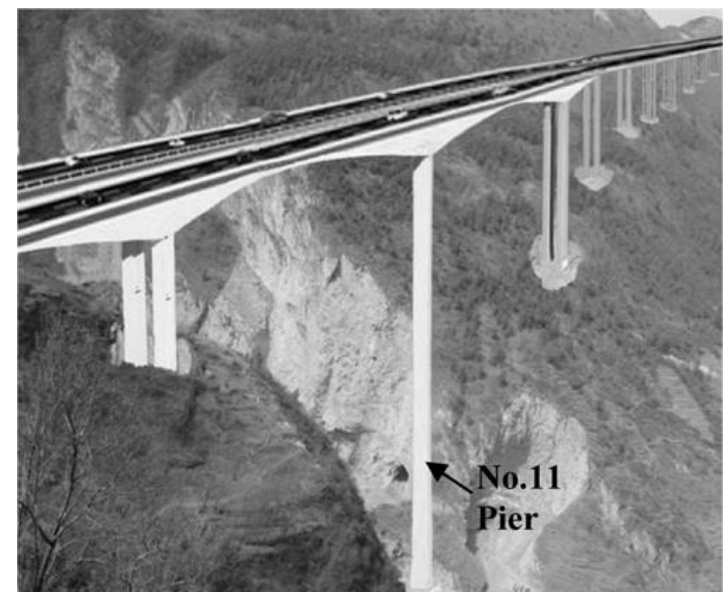

Fig. 1. Design sketch of Hezhang Bridge.

The geological layers at the bridge site are divided into the overlying stratum and bedrock. The overlying stratum is composed of $70 \%$ cobble and $30 \%$ clayey soil of medium density, which is saturated and brown and yellow in color. The bedrock is moderately weathered gray limestone. The standard value of its saturated uniaxial compressive strength is $40 \mathrm{MPa}$. Field tests based on a distributed fiber sensing technique were conducted at piles 1 and 17.

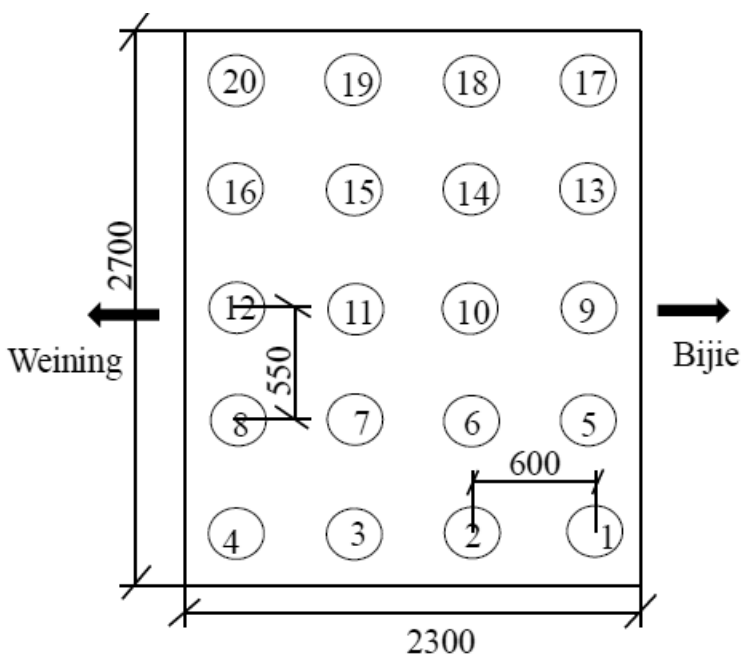

Fig. 2. Layout of the rock-socketed piles at pier site 11 (unit: centimeters). 


\section{FIELD LOAD TEST AND ITS DATA-PROCESSING}

To eliminate the eccentric load effect, two optical cables were installed along two symmetrical concrete reinforcing bars of a pile in a U-channel to form a symmetrical configuration, as shown in Figure 3. The optical cables were fixed along the reinforcing bars every $50 \mathrm{~cm}$ in a point-binding pattern.

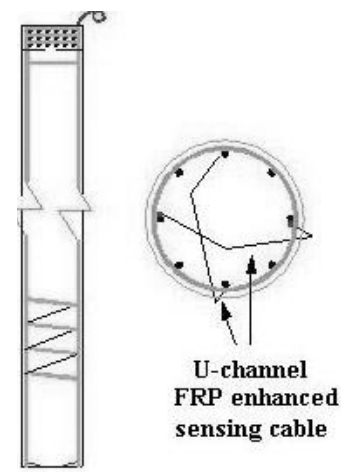

Fig. 3. Layout of optical cable.

Static loading tests were conducted on these instrumented piles using a maintained load method. After the displacement was stabilized under a certain load, fiber-optic distributed strain and temperature sensors (DSTS) produced by OZ Optics Ltd., Canada, were used to collect data from the optical cables. Axial strain profiles were derived by averaging the strain distributions from two optical fiber cables installed on opposing sides of the piles, and the axial forces were acquired through the strain and pile's elastic modulus and the cross-sectional area. Based on the axial force distribution under a different load, the unit shaft resistance can be calculated according to Eq. (1).

$$
f_{s}(z)=-\frac{1}{U} \frac{\Delta Q(z)}{\Delta z}=-\frac{A E}{U} \frac{\Delta \varepsilon}{\Delta z}
$$

where $f_{s}(z)$ is the shaft resistance of the unit at a pile depth of $z, \Delta Q(z)$ is the axial increment between two cross-sections, $U$ is perimeter of the pile, $\Delta \varepsilon$ is the strain increment, $\Delta z$ is the difference in depth between two cross-sections, $A$ is the cross-sectional area of the pile, and $E$ is the elasticity modulus of the pile, where the value of the test pile is $300 \mathrm{GPa}$.

\section{ENHANCEMENT PHENOMENON OF SHAFT RESISTANCE}

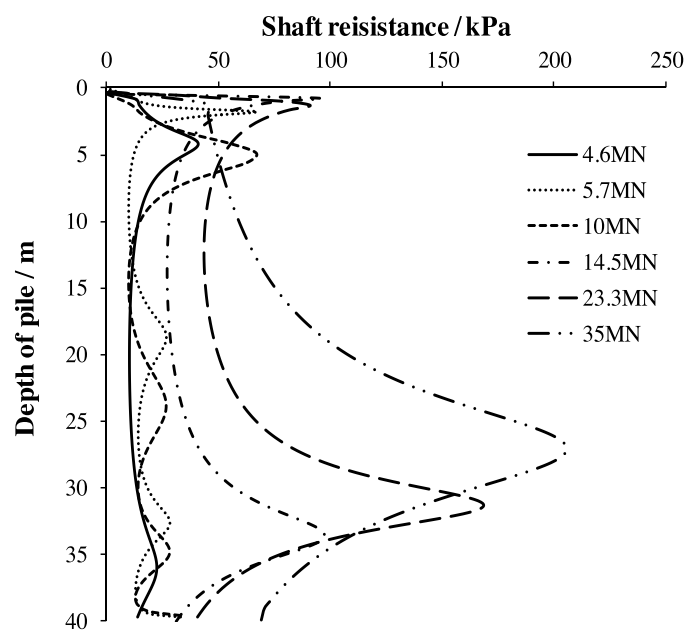

Fig. 4. Shaft resistance distribution of pile 1. 


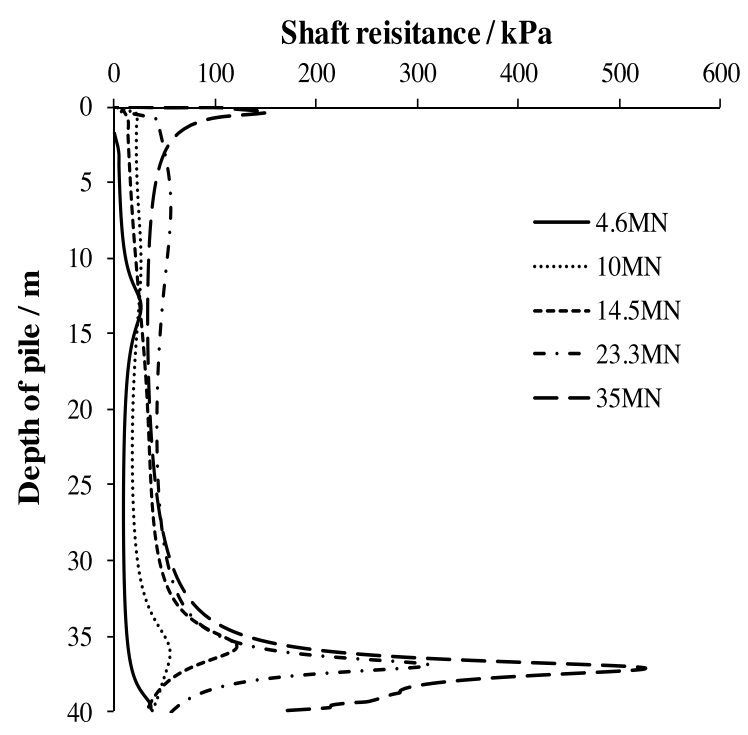

Fig. 5. Shaft resistance distribution of pile 17.

Because a portion of the concrete in the pile body is cured and segregated, the shaft resistance in the bedrock appears to fluctuate during the early loading stage. This fluctuation disappears with the increase in the upper load and does not affect the mechanical properties of the test piles.

Figures 4 and 5 show that the shaft resistance of a pile clearly increases within a certain range near the pile tip with an increase in the upper load. The enhanced range of piles 1 and 17 is approximately $5 \mathrm{~d}$ and $2 \mathrm{~d}$ ( $\mathrm{d}$ is pile diameter), respectively. Figure 6 shows the change in maximum shaft resistance with the load-sharing ratio of the tip resistance. The enhancement of the shaft resistance is directly related to this ratio. The phenomenon is not clear when the ratio is less than $10 \%$, but it becomes increasingly obvious when the ratio is greater than $10 \%$. Under the last stage load, the load-sharing ratio of the tip resistance of pile 1 is $11.14 \%$, and the maximum shaft resistance is $205.71 \mathrm{kPa}$. Simultaneously, the ratio of pile 17 is $27 \%$, and the maximum shaft resistance is $526.24 \mathrm{kPa}$, which is about 2.5 times that of pile 1 . Therefore, the shaft resistance and the tip resistance are not independent, but interact with each other. The increase in tip resistance can promote the effectiveness of the shaft resistance.

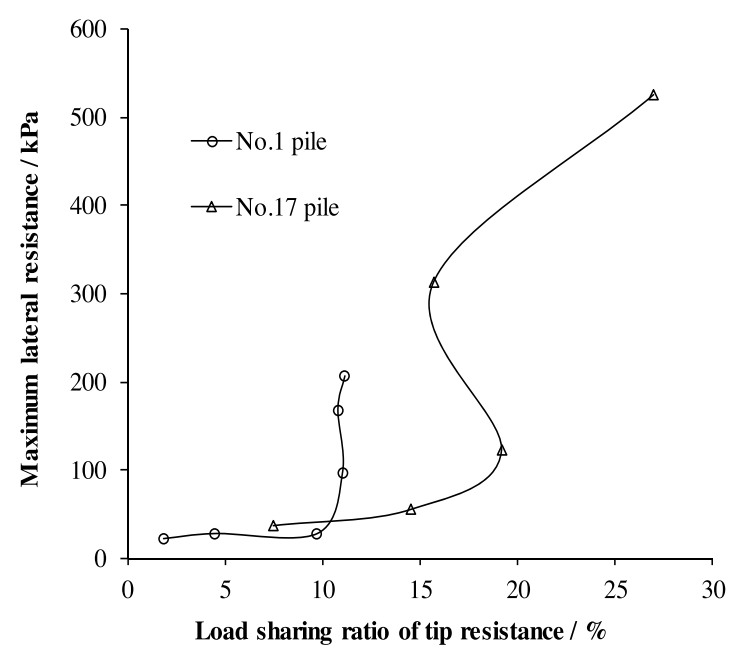

Fig. 6. Change curve of maximum shaft resistance. 


\section{LOAD CAPACITY CHARACTERISTICS OF TEST PILES}

The load-sharing ratios of the overlying stratum, bedrock, and tip of piles 1 and 17 were calculated, as shown in Figures 7 and 8, respectively, where $Q$ is the total applied load, $Q_{s}$ is the load shared by the overlying stratum, $Q_{r}$ is the load shared by the shaft resistance in the bedrock, and $\mathrm{Q}_{\mathrm{b}}$ is the tip resistance.

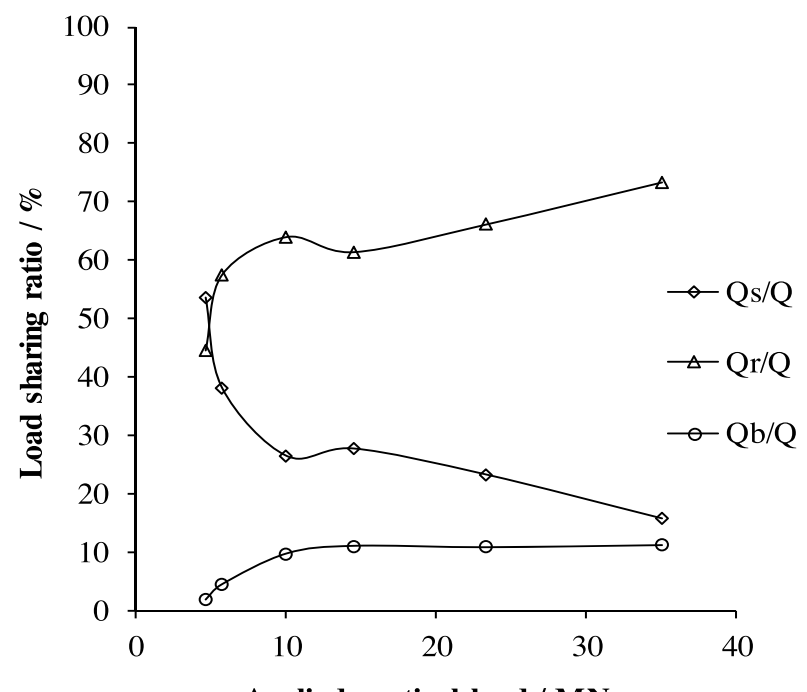

Applied vertical load / MN

Fig. 7. Load sharing ratio of pile 1.

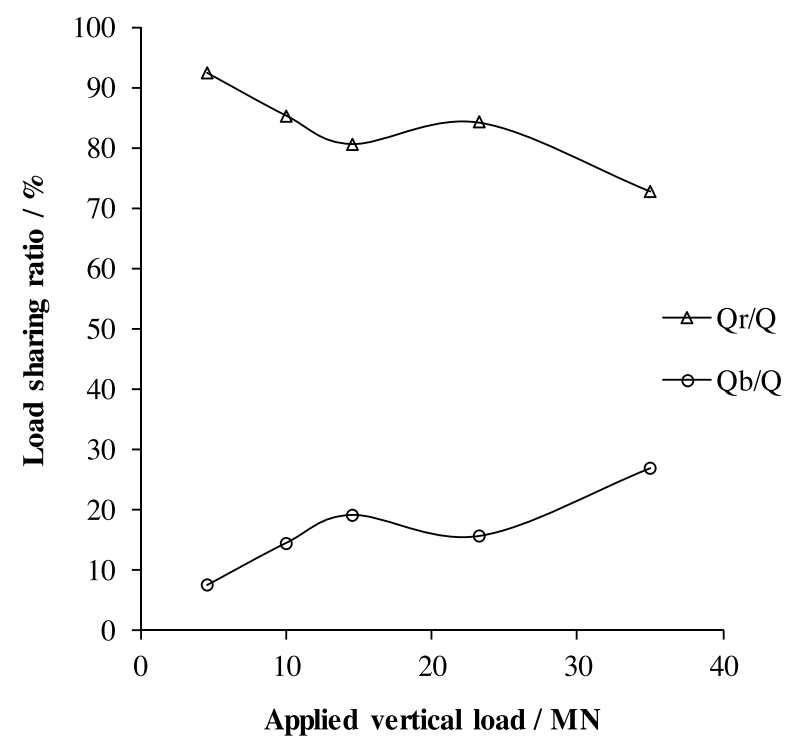

Fig. 8. Load sharing ratio of pile 17.

The overlying stratum of pile 1 is pebble soil, with a thickness of $13.2 \mathrm{~m}$, and the rock-socketed length of pile 1 is $26.8 \mathrm{~m}$. During the early stage of construction, the upper load is mainly born by the shaft resistance, and the pebble soil also bears a large proportion of the top load of the pile. The load-sharing ratio of the shaft resistance in pebble soil decreases from $53.64 \%$ to $15.61 \%$ with an increase in the upper load, which indicates that the shaft resistance is effective. The ratio of shaft resistance in bedrock increases from $44.54 \%$ to $73.25 \%$, whereas the ratio of the tip resistance increases gently from $1.82 \%$ to $11.14 \%$. 
Pile 17 is embedded in rock entirely with a rock-socketed length of $40 \mathrm{~m}$. With an increase in the upper load, the load-sharing ratio of the shaft resistance in bedrock decreases from $92.5 \%$ to $73 \%$, whereas the ratio of the tip resistance increases from $7.5 \%$ to $27 \%$. The construction loads of the two test piles are born mainly by the shaft resistance, which occurs earlier than the tip resistance. In addition, when the load function of the tip resistance is not fully utilized, the cost of the project increases.

Figure 9 shows the average and maximum shaft resistances of the test piles under each level load. The average value of pile 1 increases from 14.7 to $138.98 \mathrm{kPa}$, whereas that of pile 17 increases from 22.42 to $205.71 \mathrm{kPa}$. The maximum value of pile 1 increases from 16.0 to $187.86 \mathrm{kPa}$, and that of pile 17 increases from 37.16 to $526.24 \mathrm{kPa}$.

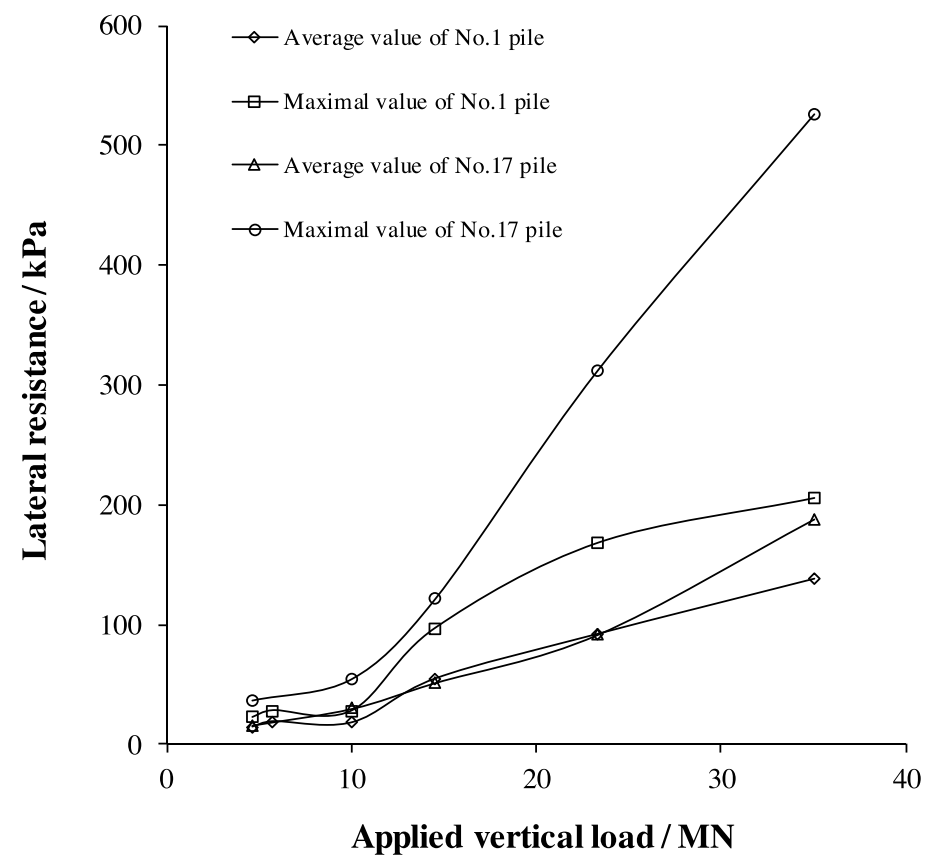

Fig. 9. Shaft resistance under each level of load.

At present, many scholars have put forward calculation methods for the shaft resistance, as shown in Table 1 (Horvath et al., 2011; Rosenberg et al., 2011; Rowe \& Armitage, 1987; Zhang \& Einstein, 1999; Charles, et al., 2001).

Table 1. Calculation methods of shaft resistance.

\begin{tabular}{|c|c|}
\hline Author & Calculation formula \\
\hline Rosenberg and Journeaux & $q_{s \max }=0.375 \sigma_{c}^{0.515}$ \\
\hline Horvath and Kenney & $q_{s \max }=(0.2 \sim 0.3) \sigma_{c}^{0.5}$ \\
\hline \multirow{2}{*}{ Rowe and Armitage } & $q_{s \max }=0.45 \sigma_{c}^{0.5}$ (smooth pore wall) \\
\hline \multirow{2}{*}{ Zhang and Einstein } & $q_{s \max }=0.6 \sigma_{c}^{0.5}$ (rough pore wall) \\
\cline { 2 - 2 } & $q_{s \max }=0.4 \sigma_{c}^{0.5}($ smooth pore wall) \\
\hline Charles & $q_{s \max }=0.8 \sigma_{c}^{0.5}($ rough pore wall) \\
\cline { 2 - 2 } & $q_{s \max }=0.19 \sigma_{c}^{0.5}$ \\
\hline
\end{tabular}

Although there are many differences between these methods, the range of calculation is as follows: 


$$
q_{\mathrm{smax}}=(0.19 \sim 0.8) \sigma_{c}^{0.5}
$$

where $q_{\text {smax }}$ is the ultimate shaft resistance, and $\sigma_{c}$ is the pile strength.

The maximum shaft resistance of pile 1 under the last loading stage is $q_{s \max }=205.71 \mathrm{kPa}=0.046 \sigma_{c}^{0.5}$, and that of pile 17 is $q_{s \max }=526.24 \mathrm{kPa}=0.126 \sigma_{c}^{0.5}$. Clearly, these values are all less than the minimum research result of $q_{s \max }=0.19 \sigma_{c}^{0.5}$.

\section{IMPROVEMENT IN DESIGN METHOD}

According to the tests results, the shaft resistance and the tip resistance of rock-socketed piles are not independent of each other, and the tip resistance can promote the effectiveness of the shaft resistance. The current Highway Code in China suggests that the load capacity of a rock-socketed pile be designed based on the shaft resistance in the soil layer and bedrock, as well as the tip resistance (JTJ D63 - 2007 design code for roadbed and highway bridge). The calculation formulas are shown in Eqs. (3) and (4).

$$
\begin{aligned}
& Q_{u}=Q_{s s}+Q_{\mathrm{rs}}+Q_{r \mathrm{p}} \\
& {\left[R_{\mathrm{a}}\right]=\frac{1}{2} \zeta_{\mathrm{s}} u \sum_{i=1}^{n} l_{i} q_{i \mathrm{k}}+u \sum_{i=1}^{m} c_{2 i} h_{i} f_{\mathrm{rk} i}+c_{1} A_{\mathrm{p}} f_{\mathrm{rk}}}
\end{aligned}
$$

where $Q_{u}$ is the ultimate load capacity of a rock-socketed pile, $Q_{s s}$ is the ultimate shaft resistance of the soil layer, $Q_{r s}$ is the ultimate shaft resistance of the bedrock, $Q_{r p}$ is the ultimate tip resistance, $c_{1}$ is the mobilization factor of the tip resistance, $A_{p}$ is the sectional area of the pile tip $\left(\mathrm{m}^{2}\right), f_{r k}$ is the standard uniaxial compressive strength of rock-saturated pile end rock $(\mathrm{kPa}), c_{2 i}$ is the mobilization factor of the shaft resistance of rock stratum I, $u$ is the pile body circumference $(\mathrm{m}), h_{i}$ is the rock-socketed length of the piles in each rock stratum $(\mathrm{m}), m$ is the number of rock strata, $\zeta_{i}$ is the mobilization factor of the shaft resistance of the soil layer, $l_{i}$ is the thickness of each soil layer $(\mathrm{m}), q_{i k}$ is the standard value of the shaft resistance of soil layer I $(\mathrm{kPa}), n$ is the number of soil layers, and the soil layer is considered to be made up of strongly weathered and completely weathered rock strata.

In this design method, the load capacity of a rock-socketed pile is determined through the linear superposition of the shaft resistance and the tip resistance. However, the shaft resistance of a pile tip is clearly enhanced with the increase in load sharing ratio of the tip resistance. The maximal shaft resistance of pile 17 reaches $526.24 \mathrm{kPa}$ at a ratio of $27 \%$, which is still less than the current minimum research result. Therefore, to fully enhance the effect of the shaft resistance, the tip resistance can adopt $30-60 \%$ of the pile top load in the rock-socketed pile design. Actually, the load-sharing ratio of the tip resistance is less than this proportion based on the enhancement of the shaft resistance. The reduction in tip resistance caused by this enhancement can be used as a safety reserve of the load capacity of a pile foundation. Synchronously, the shaft resistance of a pile in a soil layer and bedrock is still determined based on the method of the Highway Code in China. The design method based on the enhancement of the shaft resistance is as follows:

$$
Q_{u}=Q_{s s}+Q_{\mathrm{rs}}+Q_{r \mathrm{p}}=u \sum q_{i k} l_{i}+u h_{r}\left(a \sigma_{c}^{0.5}\right)+\gamma Q_{u}
$$

where $h_{r}$ is the rock-socketed length $(\mathrm{m}), a$ is the empirical reduction coefficient, and $\gamma$ is the load-sharing ratio of the tip resistance, which is adopted as $0.3-0.6$. In addition, the tip resistance should be less than the load capacity of the pile end.

The load capacity of the pile end is calculated using the method proposed by Zhang (2010).

$$
q_{p \max }=6.39\left(\sigma_{c m}\right)^{0.42}
$$




$$
\begin{aligned}
& \sigma_{c m}=\left(\alpha_{E}\right)^{0.7} \sigma_{c} \\
& \alpha_{E}=0.0231 R Q D-1.32
\end{aligned}
$$

where $q_{p \max }$ is the load capacity of the pile end (MPa); $\sigma_{c m}$ is the unconfined compressive strength of the rock mass $(\mathrm{MPa}) ; \sigma_{c}$ is the unconfined compressive strength of intact rock (MPa); and $\alpha_{E}$ is the reduction coefficient, which is 0.15 when it is less than 0.15 ; and $R Q D$ is the designated rock quality.

The steps of the design method based on the enhancement of the shaft resistance are as follows:

(1) Determine the tip resistance, and check whether it is less than the load capacity of the pile end.

(2) Determine the shaft resistance.

(3) Determine the rock-socketed length.

\section{CALCULATION VERIFICATION}

The diameter of pile 1 is $2.5 \mathrm{~m}$, the load of each pile is around $3.5 \times 10^{4} \mathrm{kN}$ on average, and the ultimate load is $7.0 \times 10^{4} \mathrm{kN}$. The designed rock-socketed length is 2.5 times the pile diameter $(6.25 \mathrm{~m})$, and the actual length is 26.8 $\mathrm{m}$. The design steps based on the enhancement of the shaft resistance are as follows:

(1) Determine the tip resistance, where $\gamma$ adopts a value of 0.5 .

$Q_{r p}=\gamma Q_{u}=0.5 \times 7.0 \times 10^{4}=3.5 \times 10^{4} \mathrm{kN}$

According to Eqs. (5)- (7), the load capacity of the pile end is

$\alpha_{E}=0.0231 R Q D-1.32=0.0231 \times 62-1.32=0.11$, where $\alpha_{E}$ adopts a value of 0.15 .

$\sigma_{c m}=\left(\sigma_{E}\right)^{0.7} \sigma_{c}=10.6 \mathrm{MPa}$

$q_{p \max }=6.39\left(\sigma_{c m}\right)^{0.42}=17.25 M P a$

$q_{p \max } A_{p}=8.45 \times 10^{4} \mathrm{kN}>Q_{r p}$

The tip resistance is less than the load capacity of the pile end.

(2) The total shaft resistance of the soil layer is

$Q_{s s}=u \sum q_{s i k} l_{i}=3.14 \times 2.5 \times 13.2 \times 100=1.04 \times 10^{4} \mathrm{kN}$.

(3) The total ultimate shaft resistance of the bedrock is

$Q_{r s}=Q_{u}-Q_{s s}-Q_{r p}=2.46 \times 10^{4} \mathrm{kN}$.

The rock-socketed length is

$h_{r}=Q_{r s} / u\left(a \sigma_{c}^{0.5}\right)=3.68 m<2.5 d$

In addition, the rock-socketed length of pile 17 when applying this method is

$h_{r}=Q_{r s} / u\left(a \sigma_{c}^{0.5}\right)=5.25 m<2.5 d$ 
The rock depths of piles 1 and 17 are optimized as 3.68 and $5.25 \mathrm{~m}$, respectively, and are reduced by 2.57 and 1 $\mathrm{m}$ compared to the design depth. The results indicate that this design method can shorten the required rock-socketed length significantly, which can achieve considerable economic benefit while still ensuring a high level of safety. The range of enhancement in lateral resistance differs under different geological conditions, and thus it is necessary to conduct a preliminary site investigation. With the development of post grouting technology, the weakening effect of the load capacity of rock-socketed piles based on the pile bottom sediment and pile side mud is significantly reduced, thereby providing technical support for the promotion of this design method. Thus, the method can be applied to the design of rock-socketed piles used in practical engineering projects. However, it is necessary to pay attention to previously accumulated experience to generate a more reasonable design of a rock-socketed pile.

\section{CONCLUSIONS}

Field tests based on a distributed fiber sensing technique were conducted to research the load capacity characteristics of rock-socketed piles. In addition, according to the test results, the design method was also improved based on the enhancement of the shaft resistance. The conclusions obtained from this study are as follows:

1. The shaft resistance and the tip resistance do not work synchronously, and the shaft resistance has an effect earlier than the tip resistance.

2. When the load-sharing ratio of the tip resistance is greater than $10 \%$, an enhancement of the shaft resistance occurs, which becomes more distinct with an increase in the ratio.

3. The improved design method based on the enhancement of the shaft resistance can take full advantage of both the tip resistance and the shaft resistance. This method can also shorten the rock-socketed length, thereby reducing the construction costs. This method can be used in practical engineering applications, and engineering experience should be gathered to achieve a more reasonable design of a rock-socketed pile.

\section{ACKNOWLEDGMENTS}

Both the National Natural Science Foundation of China (Grants No. 41272292 and 41672273) and Guizhou Provincial Department of Transportation (Projects No. 2010-122 and 2011-122-032(1)) funded this research project. This research was also supported substantially by the Key Laboratory of the Geotechnical and Underground Engineering of Ministry of Education.

\section{REFERENCES}

Carrubba, P. 1997. Skin friction on large-diameter piles socketed into rock. Canadian Geotechnical Journal, 34(2): 230-240.

Charles W.W.N., Terence L.Y.Y., Jonathan H.M.L. \& Wilson H.T. 2001. Side resistance of large diameter bored piles socketed into decomposed rocks. Journal of Geotechnical and Geoenvironmental Engineering, 127(8): 642-657.

Horvath, R.G., Kenney, T.C. \& Kozicki, P. 2011. Methods of improving the performance of drilled piers in weak rock. Canadian Geotechnical Journal, 20(4): 758-772.

Pells, P.J.N. \& Turner, R.M. 1979. Elastic solutions for the design and analysis of rock-socketed piles. Canadian Geotechnical Journal, 16(3): 481-487.

Rosenberg, P. \& Journeaux, N. 2011. Friction and end bearing tests on bedrock for high capacity socket design. Canadian Geotechnical Journal, 13(3): 324-333.

Rowe, R.K. \& Armitage, H.H. 1987. Theoretical solutions for axial deformation of drilled Piles in rock. Canadian Geotechnical Journal, 24(1): 114-125.

Rowe, R.K. \& Armitage, H.H. 1987. A design method for drilled piers in soft rock. Canadian Geotechnical Journal, 24(1): 126-142.

Seidel, J.P. \& Collingwood, B. 2001. A new socket roughness factor for prediction of rock socket shaft resistance. Canadian 
Geotechnical Journal, 38(1): 138-153.

Vipulanandan, C., Hussain, A. \& Usluogulari, O. 2007. Parametric study of open core-hole on the behavior of drilled shafts socketed in soft rock. Geo-denver, 2007(158): 1-10.

Williams, A.F., Johnston, I.W. \& Donald, I.B. 1980. The design of socketed piles in weak rock. Golden Jubilee of the International Society for Soil Mechanics \& Foundation Engineering Commemorative Volume 1.

Zhang, L. \& Einstein, H.H. 1999. End bearing capacity of drilled shafts in rock. Journal of Geotechnical and Geoenvironmental Engineering, 125(12): 574-584.

Zhang, L.Z. 2010. Prediction of end-bearing capacity of rock-socketed shafts considering rock quality designation (RQD). Canadian Geotechnical Journal, 47(10): 1071-1084.

Submitted: 30/11/2016

Revised: 23/10/2017

Accepted: 06/12/2017 


\title{
تحسين طرق تصميم الركائز الصخرية المجوفة اعتماداً على تعزيز مقاومة العمود
}

\author{
هاوفينج شينغ وجين وو \\ قسم الهندسة الجيوتقنية، جامعة تونغجى، شنغهاي، الصين
}

\section{الخلاصة}

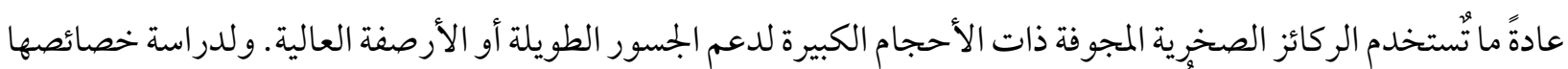

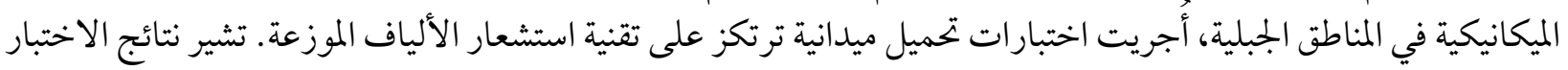

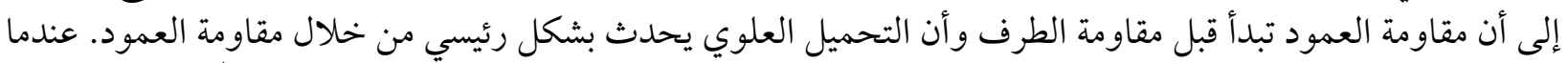

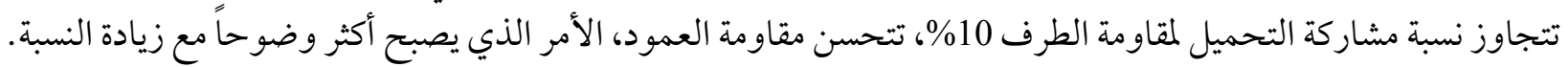

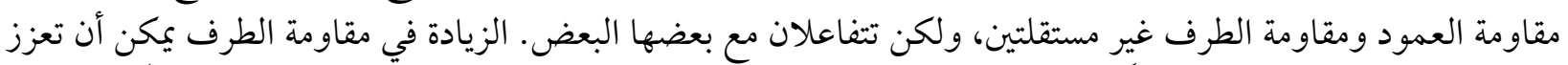

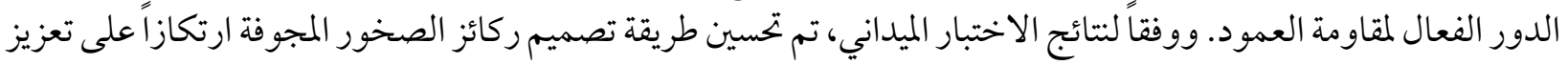

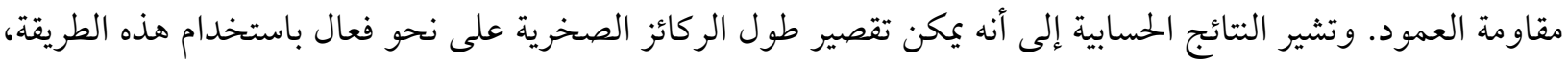
وبالتالي الحصول على فوائد اقتصادية كبيرة. 